\title{
TECNOLOGIAS, CURRÍCULO, SOLIDARIEDADE: O FUTURO DA EDUCAÇÃO PÓS PANDEMIA
}

\section{TECHNOLOGIES, CURRICULUM, SOLIDARITY: THE FUTURE OF POST-PANDEMIC EDUCATION}

\begin{abstract}
Katia Regina Gonçalves Mori ${ }^{1}$ Monica Gardelli Franco²
\section{RESUMO}

O isolamento e o distanciamento social necessários ao enfrentamento da pandemia causada pelo SARS_COV-19 causaram um impacto importante nas atividades que dependem fortemente das relações sociais. Tais impactos sobre o funcionamento da sociedade se complexificaram nos espaços escolares, em especial os sistemas públicos, que carecem de recursos e condições para manter uma rotina educacional que garanta a aprendizagem e o desenvolvimento integral dos alunos. As tecnologias, seus aplicativos e plataformas se tornaram o principal meio de superar as exigências relacionadas ao isolamento e distanciamento. No entanto, o retorno da rotina escolar nos coloca diante de imensos desafios: o abandono escolar e as defasagens de aprendizagens decorrentes da descontinuidade do processo e do programa escolar e a implementação de um currículo. Este artigo pretende provocar uma reflexão sobre o futuro da educação e a importância de um currículo voltado para a apropriação crítica das tecnologias e para o desenvolvimento da consciência solidária como elementos fundamentais para o futuro pós-pandemia.
\end{abstract}

PALAVRAS-CHAVE: Tecnologia digital da comunicação e informação. Educação. Pandemia. Currículo.

\section{ABSTRACT}

The isolation and social distancing necessary to face the pandemic caused by SARS_COV-19 had an important impact on activities that depend heavily on social relationships. Suchimp acts on the functioning of society have become more complex in schools paces, especially public systems, which lack there sources and conditions to maintain an educational routine that guarantees the learning and integral development of students. Technologies, their appli-

\footnotetext{
${ }^{1}$ Doutora em Currículo, Conhecimento e Cultura Doutora pela Pontifícia Universidade de São Paulo (PUC SP), Mestre em Currículo: Novas Tecnologias da Educação Pontifícia Universidade de São Paulo (PUC SP), Graduada em Educação pela Universidade de São Paulo (USP). Desde 1995 atua em Programas e Projetos com foco em formação de gestores e professores, em especial atenção ao desenvolvimento de práticas formativas com foco na aprendizagem. Temas centrais: Educação Integral, Educação para a Transformação Social, Flexibilidade curricular e autonomia, Competências Socioemocionais, Aprendizagem Solidária. Assessora na implementação do Ciclo Autoral na Reforma Curricular Mais São Paulo da Secretaria Municipal de Educação de São Paulo (2013-2016). Consultora da Organização dos Estados Iberoamericanos-Brasil (OEI) de 2012 a 2016. Especialista do Instituto Unibanco (2015), Instituto Ayrton Senna (2015 - 2018) entre outros. Membro da Red Iberoamericana de Aprendizaje-Servicio (Argentina) desde 2005, do Comitê Executivo da Rede Brasileira de Aprendizagem Solidária (Brasil) desde 2017 e consultora do Centro Latino-americano de Aprendizagem e Serviço Solidário (CLAYSS/Argentina) desde 2013. Vive em Lisboa, Portugal, desde abril de 2019. E-mail: katia.goncalvesmori@gmail.com

${ }^{2}$ Possui graduação em Pedagogia pela Universidade de São Paulo (1986), mestrado em Educação: Currículo pela Pontifícia Universidade Católica de São Paulo (2003) e doutorado em Educação (Currículo) pela Pontifícia Universidade Católica de São Paulo (2009). Atuou como docente da educação básica por 20 anos. Foi consultora de programas educacionais da Microsoft Brasil, atuando no âmbito nacional e internacional. Atuou também como consultora da UNESCO. Foi gerente executiva da Diretoria de Projetos Educacionais da Fundação Padre Anchieta- Centro Paulista de Rádio e TV Educativas (TV Cultura), professora no Curso de especialização em Tecnologias Aplicadas à Educação da PUCSP e professora do MBA em Gestão Escolar. Foi Diretora Geral da Associação de Comunicação Educativa Roquete Pinto, Organização Social supervisionada pelo MEC, administradora da TV Escola. Tem experiência na execução de projetos com ênfase em políticas de acesso à educação, cultura e tecnologias, e em gestão de organizações públicas e privadas, atuando principalmente nos seguintes temas: comunicação educativa, cultura, educação, tecnologia, aprendizagem, inclusão digital, TV Educativas, conteúdos educacionais digitais, avaliação e integração de mídias em educação. E-mail: mmgfranco@gmail.com
} 
cations and platforms have become the primary means of overcoming isolation and distance requirements. However, there turn to school routine presents us with immense challenges: school dropout and learning gaps resulting from the discontinuity of the school process and program and the implementation of a curriculum. This article intends to provoke a reflection on the future of education and the importance of a curriculum focused on the critical appropriation of Technologies and on the development of solidarity awareness as fundamental elements for the post-pandemic future.

KEYWORDS: Digital communication and information technology. Education. Pandemic, Curriculum. 


\section{INTRODUÇÃO}

No momento em que este artigo é produzido, vivenciamos um sentimento profundo de incerteza sobre o futuro da vida em sociedade. A eleição de 2018 associada à crise sanitária deflagrada pelo SARS-COV-19 expôs, de forma bastante enfática, crenças e valores que desrespeitam os direitos humanos, em especial dos povos e das minorias mais vulneráveis, em todas suas dimensões.

Disputas sobre melhores políticas para o controle da pandemia e seus tratamentos, o negacionismo da ciência e descolamento das orientações da Organização Mundial da Saúde, potencializaram crises econômicas e políticas gerando a cada dia mais incertezas sobre o futuro pós pandemia.

No Brasil, passados quase 2 anos do início dessa crise, presenciamos índices alarmantes de pobreza, fome, desemprego e falta de assistência social. De acordo com o PNAD, chegamos a mais de 14 milhões de trabalhadores desempregados no Brasil, uma taxa de desocupação de 14,6\%, a segunda maior da série histórica iniciada em 2012 (PNAD, 2021).

Após um longo período de conquistas sociais importantes para a maior parte da população e a despeito de um crescimento no PIB no primeiro trimestre de 2021, as manchetes diárias, como essa do Correio Braziliense, nos apontam o triste cenário do crescimento dos índices de pobreza e fome no Brasil:

O crescimento de $1,2 \%$ no Produto Interno Bruto (PIB) do primeiro trimestre de 2021 , divulgado recentemente pelo Instituto Brasileiro de Geografia e Estatística (IBGE), ficou acima das expectativas do mercado, em torno de $0,7 \%$, mas o dado aparentemente positivo mascara um problema estrutural do país: a desigualdade social crescente. Em meio à pandemia que já matou mais de 470 mil brasileiros, o aumento da pobreza é agravado pelo desemprego recorde e pela inflação que não dá trégua e encolhe o poder de compra da população do Brasil — que, para piorar, está de volta ao mapa da fome. (HESSEL, 2021)

A crise obrigou diversos setores da sociedade a buscarem caminhos para manter os padrões de vida pré-pandêmicos, mas o isolamento e distanciamento social causaram um impacto importante nas atividades que dependem fortemente das relações sociais. As orientações de fechamento e abertura do comércio se desencontram, as opiniões contraditórias de multiplicam, e os tempos de trégua, no qual há a sensação de que se está voltando à normalidade, parecem durar pouco.

Com a educação escolar não foi e não está sendo diferente. Tais impactos da pandemia sobre o funcionamento da sociedade parecem se complexificar nos espaços escolares, em especial os sistemas públicos, que carecem de recursos e condições para manter uma rotina educacional que garanta a aprendizagem e o desenvolvimento integral dos alunos.

Diante do cenário desafiador para todos, as tecnologias, seus aplicativos e plataformas se tornaram o principal meio de superar as exigências relacionadas ao isolamento e distanciamento. O e-comércio cresceu exponencialmente, os encontros familiares e as reuniões passaram a ser organizadas em ferramentas como o Google Meet, Zoom, Whatsapp. Eventos, congressos, consultas médicas foram organizados nos meios digitais, para serem realizados de forma remota. Assim também as aulas em todos os níveis, da educação infantil à superior. Mas assim como contribuiu para a continuidade de atividades dos tempos pré-epidêmicos, no campo educacional, essa estratégia também revelou e potencializou as desigualdades, já tão importantes: a do acesso à tecnologia, aos serviços de acesso à internet e das plataformas.

No âmbito da educação, o retorno das atividades presenciais e da rotina escolar nos colocam diante de imensos desafios: o abandono escolar e as defasagens de aprendizagens decorrentes da descontinuidade do processo e do programa escolar e a implementação de um currículo que, não só prepare os estudantes para as exigências do futuro, como também the ofereça recursos para enfrentar os desafios para superação das desigualdades previstas para o próximo século, relacionados ao desenvolvimento tecnológico e biotecnológico, ao desenvolvimento de uma consciência ecológica e de pertencimento à Humanidade. 
Este artigo pretende provocar uma reflexão sobre o futuro da educação e a importância de um currículo voltado para a apropriação crítica das tecnologias e para o desenvolvimento da consciência solidária como elementos fundamentais para o futuro pós-pandemia.

\section{O MUNDO DO FUTURO E O FUTURO DO MUNDO}

A vida educacional escolar nos anos de pandemia potencializou o que já era conhecido: a população da escola brasileira divide-se entre os que usufruem do poder de consumo e os que sequer têm acesso a ele. Essa divisão impacta a qualidade da educação de cada grupo, sejam eles alunos ou professores. Se, antes da pandemia, já voltávamos nossa atenção para o futuro, a realidade dos anos 20 e 21 reforçam a verdade de que o futuro não é algo pré-determinado, sobre o qual temos controle. Temos muitas hipóteses sobre o que poderá ser, mas nenhuma certeza. Vivemos em um mundo para o qual não fomos preparados, e a educação de nossas crianças e adolescentes deve considerar um futuro quase imprevisível (FRANCO, 2021).

As principais revoluções trazidas pelo avanço tecnológico concentram-se nas relações que estabelecemos uns com os outros, com o meio ambiente, o modo como aprendemos, ensinamos, como nos comunicamos e buscamos soluções para problemas, desafios locais e globais. A interconectividade entre países e culturas possibilitada pelas tecnologias produziu uma interdependência de aspectos culturais, econômicos, políticos e sanitários da sociedade contemporânea, impactando de forma definitiva o modus vivendi da atual civilização. Deflagrou também um cenário complexo e incerto que demanda planejamentos e reorganização constante. Segundo especialistas em várias áreas do conhecimento, de empresas e instituições contemporâneas estamos na era do mundo V.U.C.A, cujo acrônimo representa velocidade, incerteza, complexidade e ambiguidade (ALKMIN, 2018).

Assim como diversos setores da sociedade, da economia e da política, a educação tem sido demandada a estar continuamente atenta a esse movimento global para atender o que está determinado na Constituição Brasileira:

A educação, direito de todos e dever do Estado e da família, será promovida e incentivada com a colaboração da sociedade, visando ao pleno desenvolvimento da pessoa, seu preparo para o exercício da cidadania e sua qualificação para o trabalho. (Art 205, 1988)

Nesse contexto, os desafios globais parecem se complexificar na mesma proporção. As desigualdades, a exploração ecológica desenfreada, as guerras econômicas e ideológicas se ampliam e potencializam. E os cenários de civilização para as próximas décadas se constituem nos maiores desafios para uma proposta de educação humanizadora.

Nessa direção, identificamos as teorias relacionadas ao pensamento complexo, representadas pelo filósofo Edgar Morin e as análises histórico-sociais trazidas pelo historiador Yuval Noah Harari como essenciais para uma reflexão sobre as perspectivas do futuro da humanidade em todas as suas dimensões: econômicas, sociais e ambientais.

\section{- CONSCIÊNCIA PLANETÁRIA E DE PERTENCIMENTO À HUMANIDADE}

Recentemente, às vésperas de completar 100 anos, Edgar Morin fez um importante alerta sobre a importância da educação para o enfrentamento dos problemas globais agravados, segundo ele, pelo descontrole da globalização:

O processo de globalização ainda está descontrolado e nos conduz à possibilidade de catástrofe generalizada. Esses problemas precisam estar na educação. Para onde vamos? Onde estamos, humanos? Hoje em dia é necessário ter consciência de que pertencemos à espécie humana, que tem um destino comum frente a tantos perigos terríveis. Não existe essa consciência, mas o oposto dela. [....] A Educação precisa ensinar essa consciência de pertencimento à Humanidade (MORIN, 2019, s.p.). 
Segundo ele, a educação deve promover o desenvolvimento de uma consciência planetária, que reconheça a intensa integração e conexão entre as ações humanas, os fenômenos e saberes. A consciência de pertencimento à Humanidade é essencial para qualquer projeto educativo que tenha como referência o desenvolvimento pleno $\mathrm{e}$ integral e a compreensão de que qualquer ação pode impactar a Humanidade assim como o planeta, para o bem e para o mal.

Morin nos provoca a perceber o mundo em sua complexidade, com todas as tensões e contradições. O mundo é incerto e a educação precisa formar pessoas para viver em cenários de incertezas. A própria construção do conhecimento acontece a partir da interpretação da realidade, e não da própria realidade (MORIN, 2000). Isso mostra o desafio de educar em meio ao imediatismo e realidades das redes sociais, e de como é difícil quebrar certezas muitas vezes construídas a partir de fake news, de interesses de grupos extremistas e manipuladores.

Para esse autor, o fenômeno da aprendizagem é complexo, pois é por meio das infinitas possibilidades de conexões entre os saberes, a partir dos sentidos que os aprendizes thes atribuem que o conhecimento é elaborado. Assim, se constituem possibilidades infinitas de interpretações e intervenções no mundo. Dentro desta perspectiva, torna-se essencial que o currículo considere de forma estrutural a formação das futuras gerações para essa visão planetária.

Morin destaca a importância de se relacionar a ética da compreensão com a ética da era planetária, e para isso é preciso haver a mundialização da compreensão.

A compreensão é ao mesmo tempo meio e fim da comunicação humana. O planeta necessita, em todos os sentidos, de compreensões mútuas. Dada a importância da educação para a compreensão, em todos os níveis educativos e em todas as idades, o desenvolvimento da compreensão necessita da reforma planetária das mentalidades; esta deve ser a tarefa da educação do futuro. (MORIN, 2000, p.104)

A compreensão é fundamental para uma educação humanizadora, no sentido em que envolve ensinar a pensar em contexto ético e sustentável, considerando diferentes olhares, culturas, compreendendo as partes e o todo, o individual e o coletivo.

\section{A INTELIGÊNCIA (ARTIFICIAL) E AS NOSSAS ESCOLHAS}

Num mundo cada vez mais conectado, a inteligência artificial e os algoritmos passam a "pensar por nós" e cada vez é mais difícil perceber qual a leitura de mundo fazemos por nós mesmos e quais seriam as melhores escolhas.

Isso pode ser facilmente comprovado. Por exemplo, segundo especialistas em desenvolvimento de tecnologias, uma simples pesquisa no Google pode gerar resultados completamente diferentes de acordo com as últimas informações capturadas de cada usuário.

Se por um lado todo esse aparato gera conforto e satisfação, por outro pode ser um desastre civilizatório, dada a suposta simplificação do todo. Mauro Segura, líder de Marketing da IBM Brasil nos alerta que:

Os circuitos neurais criados ao longo do tempo dentro da nossa cabeça nos levam à percepção automática, ou seja, as nossas percepções são impulsionadas por circuitos rígidos gravados dentro do cérebro — hábitos antigos - muito mais do que pelo recebimento de dados novos do mundo. Como resultado, as pessoas percebem o mundo de acordo com suas crenças, preconceitos e atitudes, em vez de ver as coisas como são ou como poderiam ser. Os vieses que temos influenciam muito a forma como tomamos decisões. (SEGURA, 2018) [4]

Isto é, estamos perigosamente nos acostumando a tomar decisões a partir de um universo arranjado pelos algoritmos criados para gerar um vasto ambiente homogêneo e reconfortante que reafirma nossas próprias crenças, 
que nos aproxima do que acreditamos, sem trazer de fato a realidade como ela é. O problema se agrava quando esse repertório de referências é um oceano repleto de desinformação - as chamadas fakes news. As notícias falsas são criadas sem princípios éticos para defender uma ideologia, um preconceito, difamar uma pessoa e/ou uma ideia e pode gerar graves problemas para sistemas governados pela corresponsabilidade e cidadania, como as democracias. Como não é possível detectá-las pelos algoritmos, a escala de propagação pode ser exponencial com as redes sociais. O homem vive das fantasias que ele mesmo cria, e em rede. Nas palavras de Edgar Morin,

A importância da fantasia e do imaginário no ser humano é inimaginável; dado que as vias de entrada e de saída do sistema neurocerebral, que colocam o organismo em conexão com o mundo exterior, representam apenas $2 \%$ do conjunto, enquanto $98 \%$ se referem ao funcionamento interno, constituiu-se um mundo psíquico relativamente independente, em que fermentam necessidades, sonhos, desejos, ideias, imagens, fantasias, e este mundo infiltra-se em nossa visão ou concepção do mundo exterior. (MORIN, 2000, p.20)

$\mathrm{Na}$ realidade de 2020, praticamente não importa o que de fato acontece, mas sim as fantasias e desejos pessoais. Ao aliar essa informação ao interesse do desenvolvimento das tecnologias para prender qualquer usuário, vale criar um ambiente virtual que reforça as crenças pessoais? Sim, e o perigo está em formarmos pessoas que não são contrariadas, que pelas (falsas) notícias reafirmam suas crenças e selecionam com quem querem se relacionar, deletando os indesejados. O perigo está porque usamos exatamente essa tecnologia e essa lógica, também na educação.

Para que sejamos um pouco mais atentos aos perigos desse processo civilizatório, é preciso criar mecanismos de atenção intencional ao que de fato acontece em nossa maneira de ser presencial e virtual. Aprender a ser, a produzir, a relacionar-se, a viver de maneira consciente e sustentável, a construir conhecimento, e sobretudo, fazer boas perguntas e boas escolhas em meio a todas as contradições é o que se espera de uma proposta educativa baseada num currículo para a consciência de pertencimento à Humanidade.

O filósofo e historiador Harari $(2016,2018)$ apresenta os acontecimentos da história como estruturantes para compreensão não só da atualidade, mas também como referências para o "vir a ser" do futuro.

Em 21 lições para o século XXI, ele se propõe a analisar o que está acontecendo nos dias de hoje para identificar quais são os maiores desafios para nossas escolhas. "Qual deve ser o foco da nossa atenção? O que devemos ensinar para nossos filhos?" são perguntas com as quais estabelece o diálogo entre o contexto atual e as demandas para o futuro (HARARI, 2018).

Ele faz um alerta importante para o esgotamento das condições de desenvolvimento atual e seus impactos sobre a civilização a partir da compreensão de que, embora, ao final do século XX, o conhecimento associado ao desenvolvimento das tecnologias tenha gerado a percepção de que a humanidade tinha recursos e conhecimentos suficientes para o enfrentamento dos principais desafios para a promoção da vida na sua plenitude, em especial os relacionados às desigualdades sociais, econômicas e educacionais (HARARI, 2016), os avanços das ciências e das tecnologias disruptivas sobre o planeta e vida das pessoas podem gerar impactos negativos.

Ao analisar os fenômenos da vida no início do século XXI faz uma reflexão sobre o impacto da revolução tecnológica, em especial pelas TICs, pela Inteligência Artificial e pela Biotecnologia. Desde suas primeiras análises, Harari (2018) nos chama atenção para os riscos de ampliação das desigualdades e potencialização da dominação e controle proporcionado pela vigilância digital, resultantes da fusão da tecnologia, da biotecnologia e da Inteligência Artificial (IA). Ele alerta para mudanças importantes relacionadas ao futuro do mercado de trabalho, que deve ser impactado pela expulsão de bilhões de pessoas devido ao impacto da IA, que também será percebido em atividades de dominação e controle, de ameaça à liberdade, ao que ele atribui o conceito de "ditadura digital"

Mesmo se você for, e continuar a esconder de si mesmo e de seus colegas de turma, não conseguirá se esconder da Amazon, do Alibaba e da polícia secreta. Quando estiver navegando na internet, no Youtube ou lendo mensagens nas suas redes sociais, os algoritmos vão discretamente monitorá-lo, analisá-lo e 
dizer à Coca-Cola que, se ela quiser lhe vender alguma bebida, melhor seria usar o anúncio com o sujeito sem camisa, e não a garota sem camisa. Você nem vai saber, mas eles saberão e essa informação valerá bilhões. (HARARI, 2018, p.77)

Outro risco que ele destaca está relacionado ao acesso ao desenvolvimento biotecnológico, relacionado às conquistas para prolongamento da vida com qualidade. Ele chama a atenção que, num contexto de desigualdade social e econômica agravado por um mercado de trabalho cada vez mais dominado por tecnologias e incapaz de absorver a maioria da população, os super-ricos poderão ser cada vez mais empoderados biologicamente, na medida em que terão muito mais condições de usufruir os benefícios desse avanço da ciência biotecnológica:

[...] aprimoramentos em biotecnologia poderiam possibilitar que a desigualdade econômica se traduza em desigualdade biológica. Os super-ricos teriam finalmente algo que vale a pena fazer com sua estupenda riqueza. Enquanto até agora só poderiam comprar pouco mais que os símbolos de status, logo poderão ser capazes de comprar a própria vida. Se os tratamentos para prolongar a vida e aprimorar habilidades físicas e cognitivas forem dispendiosos, o gênero humano poderia se dividir em castas biológicas. (...) Em 2100, o $1 \%$ mais rico poderia não possuir apenas a maior parte da riqueza do mundo, mas também a maior parte da beleza, da criatividade e da saúde. (HARARI, 2018, p.104)

Para Harari $(2016,2018)$, se não nos atentarmos para os riscos que o desenvolvimento das tecnologias disruptivas trazem para a sociedade, teremos um futuro em que as desigualdades serão cada vez maiores, com consequências catastróficas para a maioria da humanidade e para o planeta.

\section{EDUCAÇÃO NA CULTURA DIGITAL}

Nesse período, a sociedade precisou se reorganizar para o fazer educacional que foi fortemente impactado pelo isolamento e distanciamento social e pelas desigualdades no acesso tanto dos professores, quanto dos alunos.

Solidariedade e responsabilidade pelo bem-estar coletivo têm sido a tônica nesse cenário, as tecnologias surgem como a principal estratégia de manutenção de uma "certa normalidade". Ao mesmo tempo, se configuram como as grandes difusoras de informações que causam equívocos na compreensão do fenômeno social ao qual todos estamos submetidos.

Muito se fala sobre novas referências para a educação, para um novo padrão de normalidade. Muito tem sido dito sobre as metodologias (presenciais, remotas). Mas será que refletir sobre metodologias e acesso às tecnologias é suficiente? Estaremos respondendo aos principais impactos da crise sanitária no desenvolvimento humano?

Para refletirmos sobre essas questões é relevante compreendermos a importância das tecnologias da comunicação e informação na educação e quais reflexões são necessárias para a consolidação da educação na cultura digital, a partir dos conceitos: educação com tecnologias e mundo digital como espaço de interação, aprendizagem e construção de conhecimento coletiva, compartilhamento e acesso ao conhecimento.

\section{EDUCAÇÃO COM TECNOLOGIAS}

As tecnologias da comunicação e informação foram sempre, de alguma forma, presentes na educação. Desde os primórdios do rádio e TV podemos identificar o papel das TIC como recurso de potencialização do acesso à educação e à cultura. Mas só a partir dos anos 90 , com a expansão do acesso aos computadores pessoais e o advento da Internet é que se constitui como um recurso fundamental para as práticas educativas. Estudos, formações e políticas públicas se estruturaram, desde então, para possibilitar a apropriação e uso das tecnologias nas práticas educacionais.

As primeiras ações e políticas foram direcionadas à apropriação das TIC para uso pedagógico e educacional. 
As formações e os equipamentos tinham como foco a tecnologia como recurso didático e apoio à melhoria da docência e da aprendizagem- metodologia e prática.

- Tecnologia como ferramenta de apoio à didática: recursos de apresentação, vídeos, simulações, recurso de comunicação, formatação e armazenamento.

- Tecnologia como ferramenta de monitoramento de aprendizagem: registro de percursos de aprendizagem, avaliações, monitoramento.

- Tecnologia como objeto de ensino: robótica e programação.

Observamos que ainda é muito presente e enfatizado nas propostas educacionais o uso da tecnologia como recurso didático.

\section{MUNDO DIGITAL COMO ESPAÇO DE INTERAÇÃO, APRENDIZAGEM E CONSTRUÇÃO DE CONHECIMENTO COLETIVO}

Este conceito está relacionado ao mundo digital possibilitado pelos ambientes virtuais como portais, redes sociais, serviços de mensagens instantânea, e mais especificamente os desenvolvidos para finalidade educacional. É o local configurado como espaços digitais onde processos formativos se realizam, independente de uma intencionalidade pedagógica. Podemos compreendê-lo a partir da análise dos recursos tecnológicos disponíveis para a finalidade educativa e pedagógica:

- Tecnologia e ciberespaço como lugar de armazenamento e distribuição de conteúdo educativos: Google, plataformas de conteúdo educativo (TVs educativas, Khan Academy, etc)

- Tecnologia e ciberespaço como lugar de pesquisa, interação, produção e distribuição de conhecimento: acesso a espaços como museus, bibliotecas, canais de distribuição como youtube, redes sociais

- Tecnologia e ciberespaço como lugar de autoria e compartilhamento: Facebook, Telegram, Whatsapp, Zoom, Teams

\section{EDUCAÇÃO À DISTÂNCIA E ENSINO REMOTO}

A possibilidade de empregar o uso das tecnologias digitais para seguir a vida de maneira virtual enquanto o presencial era regrado pelo isolamento marcou o mundo em 2020 e 2021. Para além da educação à distância, (proposta educativa estruturada, com recursos e metodologias definidos e por visar proporcionar atividades organizadas de maneira síncronas e assíncronas), as escolas buscaram o ensino remoto (em regime de urgência, todos os professores foram envolvidos na medida do possível num processo de adequação em um curto espaço de tempo). Por melhor que sejam as equipes, o processo é absolutamente estressante e aquém da qualidade idealizada (HODGES, MOORE, LOCKEE, TRUST E BOND, 2020[3]).

O caráter de urgência, os desafios de diferentes níveis (e desiguais de infraestruturas, tecnologias, letramento digital etc.) provocou a capacidade de respostas articuladas, de colaboração, de relações de confiança, de compreensão que precisam acontecer, especialmente porque vivemos num mundo de incertezas e ninguém sabe de fato o que irá acontecer (MORIN, 2000; HARARI, 2018).

\section{CURRÍCULO E SOLIDARIEDADE NO MUNDO PÓS PANDEMIA}

A complexidade da gestão da pandemia quer seja em nível internacional ou local, coletivo ou individual, nos faz repensar quanto de nossos esforços ao oferecer a formação básica de nossas crianças e jovens nas escolas conversam com uma proposta educativa à altura de tais desafios. O processo de aceleração da entrada das tecnologias da informação e da comunicação em todos os aspectos de nossas vidas com a pandemia parece trazer, ao mesmo tempo, mais soluções e mais desafios. 
Nesses tempos, fica evidente a importância das redes colaborativas (em contraponto às respostas burocráticas, padronizadas e engessadas) locais e globais e das tecnologias. Em março, o mundo já contava com centenas de cientistas trabalhando colaborativamente para indicar as principais medidas de contenção da propagação da doença enquanto se buscava conhecer as causas, os sintomas, a cura e a vacina.

Enquanto isso, redes colaborativas se organizavam também para todos os demais aspectos da vida em sociedade. Aqueles que estavam à margem da informatização, quer seja por falta de acesso à hardware, conexão com a internet de qualidade e letramento digital, ficaram impossibilitados de ter a melhor experiência.

As TICs trazem um universo de possibilidades, mas atendem ao desejo e aos interesses inclusivos e/ou excludentes.

Porque a educação é maior do que a preparação para os exames, precisamos formar pessoas capazes de conviver umas com as outras, de compreender, de gestar soluções para problemas complexos. Os desafios atuais nos mostram a importância da capacidade de resiliência, de colaboração, de criatividade, de lidar com a complexidade (MORI, 2021).

Um currículo alinhado com os ideais éticos, que não dicotomiza formação ética e cidadã do manejo das ciências e tecnologias, precisa de fato encontrar espaço na sala de aula de cada professor.

\section{CONSIDERAÇÕES FINAIS: A CULTURA DIGITAL COMO CURRÍCULO}

O cenário complexo e incerto da atualidade exige planejamentos flexíveis, que correspondam a futuros próximos. No âmbito da educação, essa característica é muito desafiadora, pois projetos educacionais não só levam em consideração a garantia do direito ao conhecimento já acumulado historicamente, mas também, o desenvolvimento de competências e habilidades essenciais para a vida agora e a futura.

Os efeitos de rede das tecnologias têm mais poder e mais alcance. O meio digital mudou por completo nossas vidas e veio para ficar. A humanidade tem muitos lados obscuros e a tecnologia está potencializando o que é a humanidade de fato. Se quisermos utilizar toda essa força científica e tecnológica para o desenvolvimento humano e sustentável, para gerar riquezas pessoais, coletivas e ecológicas, o foco está em formar pessoas conectadas com os desafios locais e globais, conscientes e corresponsáveis. A consciência humanitária implica no exercício da responsabilidade, da solidariedade, da valorização da vida (ALMEIDA, 2020).

Nesse sentido, é preciso criar práticas pedagógicas da convivência presencial e virtual e não apostar que elas se regulem por si, pois como vimos, o algoritmo tem trabalhado no intuito de ocultar diferenças e diversidades. É preciso criar experiências educativas contextualizadas em territórios de convivência e aprendizagem. É preciso enfrentar o desafio de não criar um currículo que ensine a se acostumar em saber respostas prontas, mas sim em fazer boas perguntas que geram pistas para enfrentamentos coordenados. É preciso reconhecer a cultura digital como currículo (ALMEIDA e SILVA, 2014).

A cultura digital se estabelece a partir do uso que se faz dos recursos que a tecnologia nos oferece. O impacto desta cultura no cotidiano e na vida das pessoas influencia e determina, muitas vezes, o comportamento humano. Além do uso das tecnologias para a melhoria da qualidade das práticas pedagógicas e o uso dos recursos e do mundo digital para garantia do direito à educação de qualidade para todos, é fundamental que propostas educacionais incluam, em seus currículos, reflexão e análise crítica sobre o impacto das tecnologias nas nossas vidas. A quem elas beneficiam? Somos usuários conscientes? O avanço tecnológico está disponível a todos? São vários aspectos que devem ser considerados âmbito da educação, que tem como função essencial promover o desenvolvimento de uma consciência que de fato possibilita tomadas de decisões éticas e responsáveis. É fundamental que se compreenda a cultura digital como um campo repleto de idiossincrasias e riscos subliminares. É papel da escola promover espaço para essa reflexão. Destacamos alguns pontos para justificar a importância de considerarmos a cultura digital como currículo:

- $\quad$ impacto das TDICs na alteração das relações interpessoais no mundo digital: os conceitos de 
presencialidade e as relações intergeracionais vem sendo muito impactados pelo avanço das tecnologias, muitas vezes de forma negativa e para prejuízo das relações. Refletir sobre os benefícios e malefícios decorrentes do uso das tecnologias nos relacionamentos é crucial num currículo que considere o desenvolvimento consciência de pertencimento à Humanidade e a solidariedade.

- A potencialização das desigualdades no acesso e na produção do conhecimento: entre os temas a serem objeto de reflexão na escola está relacionado a leitura crítica sobre a presença e o impacto das tecnologias na vida das pessoas, em especial o acesso e o quanto as desigualdades estão e podem ser ampliadas nessas condições. A pandemia deflagrou a falta de acesso às tecnologias e aos recursos digitais, em especial nas escolas públicas. Compreender criticamente essa realidade contribui para o fortalecimento da consciência sobre o acesso aos bens culturais como direito humano.

- Poder no mundo digital - dominação $x$ autonomia: Esse, talvez, se constitua como o ponto mais relevante para a formação das futuras gerações. Como podemos observar pelos alertas do filósofo Harari (2018) a utilização da inteligência artificial necessita de uma reflexão crítica e ética. A favor de quem, do que, para quem e para que são questões que podem nortear uma compreensão crítica sobre o papel da inteligência artificial na vida das pessoas. Observamos o quanto a IA influencia quando buscamos alguma informação nas redes ou na internet. Quase imediatamente, nossas redes sociais, as páginas de notícias que acessamos são abarrotadas com as informações e publicidade sobre a informação. A percepção de que nossa compreensão de mundo pode estar sendo manipulada e formada por uma inteligência artificial programada para essa finalidade deve ser objeto de reflexão no contexto do currículo. Além disso, os avanços tecnológicos permitem que qualquer um seja criador de conteúdo, sem que se tenham critérios claros e definidos sobre a veracidade dos conteúdos compartilhados. O desenvolvimento da consciência crítica vai possibilitar que não apenas os estudantes observem o comportamento das redes e estejam preparados para perceber a manipulação, mas como também se tornem responsáveis por produções e compartilhamento dos conteúdos.

O desafio para a sustentabilidade da vida planetária é imenso. Torna-se cada vez mais urgente compreendermos criticamente a realidade em que vivemos a partir de uma perspectiva histórica, cultural, econômica e política identificando os avanços e desafios sociais, tecnológicos e econômicos a serem superados. Só assim, poderemos ter um currículo alinhado com os contextos reais e com metas de aprendizagem voltada para a superação de desafios locais e globais, na perspectiva de um mundo melhor para todos. Um currículo que tenha a solidariedade como eixo estruturante. Como diz Dalai Lama "a mudança começa em você".

\section{REFERÊNCIAS}

ALMEIDA, Fernando José de. Ameaça da pandemia ao currículo: decifra-me ou devoro-te! in De Wuhan a Perdizes. Trajetos educativos. Fernando José de Almeida, Maria Elizabeth B. de Almeida, Maria da Graça Moreira da Silva (orgs). - São Paulo: EDUC, 2021, p. 66-77.

ALMEIDA, Fernando José; SILVA, Maria da Graça Moreira. O currículo como direito e a cultura digital. Revista e-Curriculum, v. 12, n. 2, maio-out, 2014. Disponível em: https://www.redalyc.org/pdf/766/76632206008.pdf. Acesso em: 5 mar. 2021.

ALKMIN, Alessandra. Mundo VUCA. 18 mar 2018. Disponível em: https://www.youtube.com/watch?v=ZuEF76Xs_ Mw. Acesso em: 02 mar. 2021.

CONSTITUIÇÃO (1988). Constituição da república federativa do Brasil. Brasília, DF: Senado Federal: Centro Gráfico, 1988. 
HESSEL, Rosana. Apesar do crescimento do PIB, dados mostram que o Brasil nunca foi tão desigual. Correio Brasiliense. DF, 07 de junho de 2021. Disponível em: https://www.correiobraziliense.com.br/economia/2021/06/4929384-apesar-do-crescimento-do-pib-dados-mostram-que-brasil-nunca-foi-tao-desigual.html. Acesso em: 15 ago. 2021.

FRANCO, Mônica Gardelli. Os currículos em tempos de incertezas. In: ALMEIDA, Fernando José de; ALMEIDA, Maria Elizabeth B. de; SILVA, Maria da Graça Moreira da. (orgs). Nuvens e redes: "quantos nós, dentro de nós"? São Paulo : EDUC, 2021.

HARARI, Yuval Noah. 21 lições para o século XXI; tradução Paulo Geiger. 1. ed. São Paulo: Companhia das letras, 2018.

Homo Deus: uma breve história do amanhã. 1.ed. São Paulo: Cia das Letras, 2016.

HODGES, Charles.; MOORE, Stephanie; LOCKEE, Barb; TRUST, Torrey; BOND, Aaron.The Difference Between Emergency Remote/Teaching and Online Learning. Disponível em: https://er.educause.edu/articles/2020/3/the-difference-between-emergency-remote-teaching-and-online-learning. Acesso em: 20 dez. 2020.

MORI, Katia Regina Gonçalves. Currículo, conhecimento pertinente e conhecimento emancipação solidariedade. In: ALMEIDA, Fernando José de; ALMEIDA, Maria Elizabeth B. de; SILVA, Maria da Graça Moreira da. (orgs). Nuvens e redes: "quantos nós, dentro de nós”? São Paulo: EDUC, 2021, p. 66-77.

MORIN, Edgar. Resistência, um tema fundamental para a educação hoje. Entrevista concedida à Audrei Furlaneto. GLOBO, Rio de Janeiro, 07 jun. 2019. Disponível em: <https://oglobo.globo.com/sociedade/resistencia-um-tema-fundamental-paraeducacao-hoje-diz-edgar-morin-23723303>. Acesso em: 20 jan. 2021.

Os sete saberes necessários à educação do futuro. Tradução de Catarina de Edgard de Assis Carvalho.

4. ed. São Paulo: Cortez; Brasília, DF: UNESCO, 2000.

PESQUISA NACIONAL POR AMOSTRA DE DOMICÍLIOS (PNAD) 2021. Disponível em: <http://www.ibge.gov.br>. Acesso em: 28 ago. 2021. 